\title{
材料分野の数值デー父解析用数式をXML 形式化する際の問題点 The problems for XML formalization of the formulas for numeric data analysis of the materials field
}

\author{
芳須 $弓_{厶}{ }^{1^{*}}$, 原田幸明 ${ }^{1}$, 藤田充苗 ${ }^{1}$,芦野俊宏 ${ }^{2}$ \\ Hiroshi YOSHIZU ,Kohmei HALADA ,Mitsutane FUJITA ,Toshihiro ASHINO
}

\section{*1 物質口材料研究機構}

National Institute for Materials Science

干 305-0047 茨城県つくば市千現 1- 2-1

E-mail: YOSHIZU.Hiroshi@nims.go.jp

2 東洋大学

Transdisciplinary research Integration Center, Toyo University

干 112-8606 東京都文京区白山 5-28-20

E-mail: ashino@acm.org

セマンティック Web 技術を用いて,材料問題解決支援システム構築の問題点抽出を進めている. 本報告は,材料の力学問題解決に必要な材料特性データやデー夕解析に用いる解析モデル式な どの収集を行い,データ解析て数式を取扱暢合のXML 記述の問題点について検討した .乥の結 果, 数式をXML 形式であるMathML によl启述する場合, 材料分野において数式て使用する文字 や記号の統一と数式の理解を共通化することで円滑なデー夕解析作業が可能である.乥こで,統一 した文字や記号を提案し,兴の活用例を示した。

We tried to construct the solution supported system for problems in materials field using semantic Web technologies and pointed out necessary functions. In this report, mechanical properties data and model formulas for analysis of data were collected in order to resolute mechanics problems. And then the application of the MathML, that was XML description in the formula to the system was examined. Consequently, in order to solute smoothly data analysis and the problem in materials field was enabled by communalizing unification of the character and symbol which are used with the formulas that were expressed by MathML. Thus, the unification were proposed and an example of the application was introduced.

キーワード:セマンティック Web ,材料問題解決支援システム, XML , 数式, 機械的特性, Semantic Web, Solution Supported System for Problems of Materials Field, XML, Formula, Mechanical Properties 


\section{1 はじめに}

発展しつつあるセマンティック Web 技術により材料問題解決のための支援シ ステム構築の問題点を検討してきた[1] . システムが取り扱う材料情報の記述形式 として XML が不可欠であり，材料特性 などの数値データや必要な情報の提供サ イトの記述形式を共有する必要性を示し た。材料分野の情報記述の共有化につい ては，MatML[2]があり，VAMAS 標準化 活動でNMC-MatDB[3]として，また最近 では NEDO のプロジェクトを通して世 界共通の書式 Materials Ontology[4]とし て提案されている.

バーナーズ・リーの階層図の提案にし たがって，XML (データ記述) , RDF (デ 一タの所在場所), 光して OWL (語彙の 関係，材料オントロジ) を用いてシステ ム上での情報の連携を考え, 問題解決へ の手順例を検討してきた[5] . 本報告では， 材料強度の比較などの問題解決に必要な 数值データを XML 形式で記述し, 弚れ らのデータ解析に必要な数式の取扱いに ついて調べた . 数式についても XML 形 式で記述されていることが必要であり， W3C から MathML[6]か潅告, 公表されて いる. 光こで、必要な数式を MathML 形 式により記述した 。

\section{2 材料問題解決支援システムの}

\section{設計概念}

\section{1 システムに必要な機能}

材料問題を解決するための必要な情報， 材料データベース (以下、データベース を DB と略)，材料特性データ，光してデ
一タ解析のための数式などの材料情報を 連携して問題解決の支援をするものであ る.前述したようにすでに材料 DB 記述 の枠組み (NMC-MatDB) や材料特性デ 一タの XML 化については実現している [7].Web 上には，専門書誌，規格，特許， 報告書, 特性数值 DB, 弚して材料力夕 ログなど多くの情報があり，日々更新さ れている.支援システム構築にあたって， これらの情報の中から必要とする情報を 容易に検索できる機能が必要である . 光 のため，検索を容易にするための各種の 辞書を整備し，光れらを検索の際にキー ワードとして用いることによって，的確 な情報を容易に見出せることを示した [1] .さらに , 支援システムに必要な機能 として, 材料 DB や実験から得られる数 值データの解析を行う機能が必要である.

\section{2 数値デー多解析}

材料分野では，種々の条件で実験を行 うか、材料 DB から材料特性などの数值 データを得て、実験条件と特性の関係を 種々のモデルに基づいた数式を用いてデ 一夕解析を行う. 兴の結果を基に材料現 象の明確化や構造物の設計指針が策定さ れている. 弚の解析概念を図 1 に示す. 数値データ解析には、XML で記述された 実験条件と特性からなる数值データを材 料分野の数式 DB から目的に応じた数式 を検索して、光の数式を用いてデータ解 析し，弚の結果を表やグラフとして表示 する機能が必要である . 数式 DB の数式 は MathML 形式にしたがって記述すると より容易に数式の共有が可能である.

次節ではこの数式情報について MathML 形式による数式記述を述べる. 


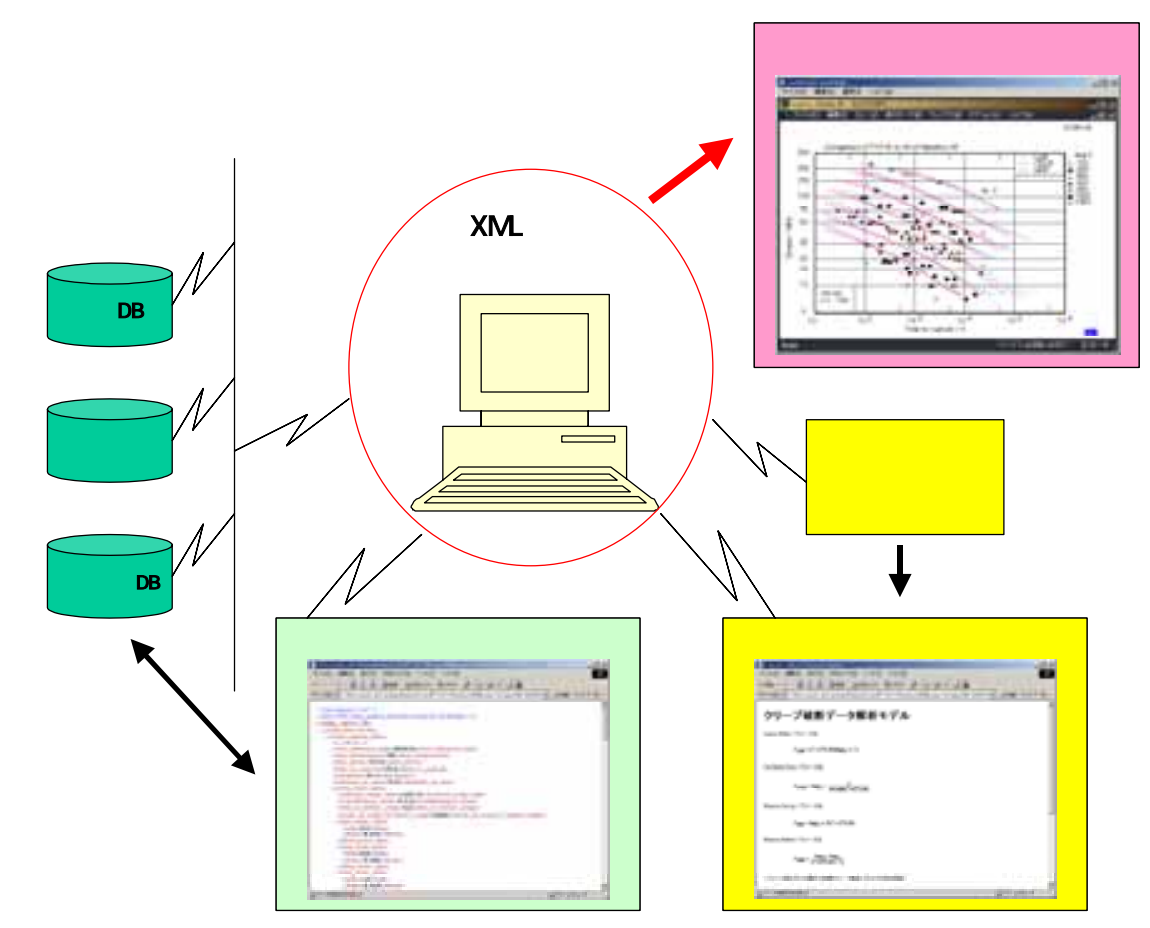

図 1 材料問題解決支援システムにおける数値デー夕解析の概念図

\section{MathML による数式記述}

データ解析に必要な数式の XML 記述 は MathML があり，この形式にしたがう ことにする．しかし，材料分野で使用さ れる数式は, 材料の専門領域によって数 式の文字や記号の意味が異なることがあ る. 兴のためには, 材料分野でも専門領 域に限定して使用されている文字や記号 の意味の統一がまず必要になる .艺こで， 材料の強度を対象とする構造材料の機械 的特性に関する数式を MathML で記述す る際の問題点について以下で検討する .

\section{1 数式の文字 記号}

はじめに, 材料の強度を対象とした場 合の数式を記述する文字や記号について 調へたた 、光の記号や式を図 2 に示す．材 料に引張荷重を加えた場合を想定してみ ると, 材料は引張荷重 $(F)$ の増加とと

$$
\begin{gathered}
\sigma\left(S_{y}, S_{T}\right)=\frac{F}{A_{0}} \quad \sigma_{T}\left(S_{T}\right)=\frac{F_{\max }}{A_{0}} \\
\delta=\frac{L_{f}-L_{0}}{L_{0}} \quad \varphi=\frac{F_{0}-F}{F_{0}} \\
F_{\max }: \text { 最大引張荷重 } \\
A_{0}: \quad \text { 試験片の原断面積 } \\
\left.\mathrm{S}_{\mathrm{y}}: \quad \text { 降代強度 } \mathrm{Q} .2 \% \text { 耐力 }\right) \\
\left.\sigma_{\mathrm{T}} \$_{\mathrm{T}}\right): \text { 引張強さ } \\
\delta: \quad \text { 破断伸び } \\
L_{0}: \quad \text { 試験前の標点距離 } \\
L_{f}: \quad \text { 試験後の標点距離 } \\
F_{0}: \quad \text { 試駼前の断面積 } \\
F: \quad \text { 試験後の断面積 }
\end{gathered}
$$

图 2 材料の強度に関する数式,記号

もに弾性変形から塑性変形をへて最後に

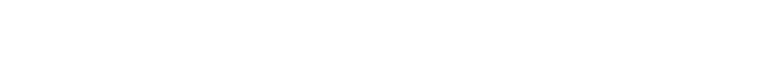
定され,データベースに収録されている． 
材料の強度は弾性変形から塑性変形に移 行しはじめる強度を降伏強度 $(0.2 \%$ 耐 力）と呼び $\mathrm{S}_{\mathrm{y}}$ るいは。 yで示される . ま た，最大引張荷重を示したところを引張 強さ $\mathrm{S}_{\mathrm{T}}$ るいは $\sigma_{\mathrm{T}}$ と呼ぶ. 強度は材料の 単位面積当たりで表され，S $\mathrm{S}_{\mathrm{T}}$ るいは $\sigma_{\mathrm{T}}$ は, 負荷荷重 (F) /面積 $(A)$ で算出されM $\mathrm{Pa}$ a単位が用いられる.また，材料を引 張ると変形して伸びるが, 兴の伸びはる で表され, 材料の強勒性やねばさの指標 として破断時の最終変形量として絞り $\varphi$ が1つの指標になる .これらは， $\delta=\left(L_{f}\right.$ $\left.-L_{0}\right) / L_{0} \times 100, \varphi=\left(F-F_{0}\right) / F_{0} \times 100$ で表さ れ，\%の百分率で表される .

引張強さに $\mathrm{S}_{\mathrm{T}}$ るいは $\mathrm{T}_{\mathrm{T}}$ 使用され ているように数式に用いれる記号が同じ でも意味することが異なる場合があるの で、添え字を含めた文字や記号の意味す ることの統一と共有が必要である .

\section{2 クリーフ特性解析用数式の記述}

一定温度で一定の負荷荷重が加わる 環境下では, 材料は時間の経過とともに 変形して破断に至る.この現象をクリー プと呼び，高温で使用する材料ではこの クリープ特性が機器設計に重要となる . クリープ強度に関する数式は, 前節の引 張強さの数式に温度の影響因子が加わっ たものとなる.クリープ特性は, 材料に 樣々な温度で樣々な荷重を負荷した数 10 組の試験を行って，乥のデータをもと にして負荷荷重と温度の関数によりはじ めてクリープ破断に耐える時間が与えら れる. 光の基本関数もクリープ破断の実 験值を評価する専門的な数式がいくつか あり，弚の数式を図 3 に示す.デー夕解
クリープ破断データ解析モデ -

Larson-Miller バラメータ法

$$
P_{\mathrm{LM}}=(T+273.15)\left(\log _{R}+C\right)
$$

Orr-Sherby-Dorn バラメータ法

$$
P_{\mathrm{OSD}}=\log _{R}-\frac{Q}{19.1425(T+273.15)}
$$

Manson-Succop パラメータ法

$$
P_{M S}=\log _{R}+B(T+273.15)
$$

Manson-Haferd バラメータ法

$$
P_{\mathrm{MH}}=\frac{\log _{R}-\log _{a}}{(T+273.15)-T_{a}}
$$

応力の多項式回帚

$$
\begin{aligned}
& P=b_{0}+b_{1} S+b_{2} S^{2}+\cdots+b_{k} S^{k}+e_{i} \\
& T_{K}=\text { Temperature (deg C) }+273.15 \\
& Y=\log \left(\mathbf{t}_{\mathbf{R}}\right) \\
& t_{R}=\text { Time to rupture }(\mathrm{h}) \\
& S=\log (\sigma) \\
& \sigma=\text { Stress (MPa) } \\
& b_{\mathbf{0}}, b_{\mathbf{1}}, b_{\mathbf{2}}, \cdots, b_{k}=\text { Regression Coefficient } \\
& k=\text { Degree of Regression } \\
& e_{i}=\text { Error Term }
\end{aligned}
$$

图 3 クリプ特性に関する数式

析では、これらの数式を用いて所定の材 料のクリープ特性を最も正確に表す数式 が選択され、光の材料のクリープ特性が 把握される . この解析には、材料 DB や 実験により得られた数値データが使用さ れるが、前述したこれらの材料情報は XML による記述が進められているが、 れらのXML 記述には、数式記述を考慮 してタグとなる要素に単位などとともに 文字や記号の属性をも指定すべきである．

\subsection{MathML の記述方法}

MathML では表示と内容の記述形式が 
MathML では表示と内容の記述形式があ る.例えば，表示 MathML では関数名や 変数名などの識別子を表す $<\mathrm{mi}>$, 演算子 や区切り記号を表す $<\mathrm{mo}>$ ，光して数值を 表す $<\mathrm{mn}>$ などのタグにより数式が図 2 に示した数式のように表される.内容 MathML は Mathematica[8]などの解析用 ソフトウェアで解析するための形式で表 現される . 例えば, 演算子は<plus>, 数 值は< $\mathrm{cn}>$ で表され、数式の内容 (処理) を理解できる形式である. 図4に示した MathML 記述例はクリープ破断データを 解析する Larson-Miller パラメータ式の例 である . 左に表示，右に内容 MathML で 記述した。また，前述した図 3 は表示 MathMLて記述した数式を Web ページに
組み込んで表示した例である . 後述する 数值データ解析では内容 MathML で記述 した数式を Mathematica で利用した例を 述べる。

\section{4 数式の利用例解析}

Mathematica による数式利用例を図 5 に示す. 図 5 では数式に使用される変数 の説明，上段の四角囲い部分は Mathematca での MathML 形式の数式をイ ンポートする命令文, 中段の四角囲いは インポートした数式の表示、乥して下段 の四角囲いは計算結果である。この手順 により, Web 上の数式と解析ソフトウェ アの連携 (Mathematica 利用に際しては

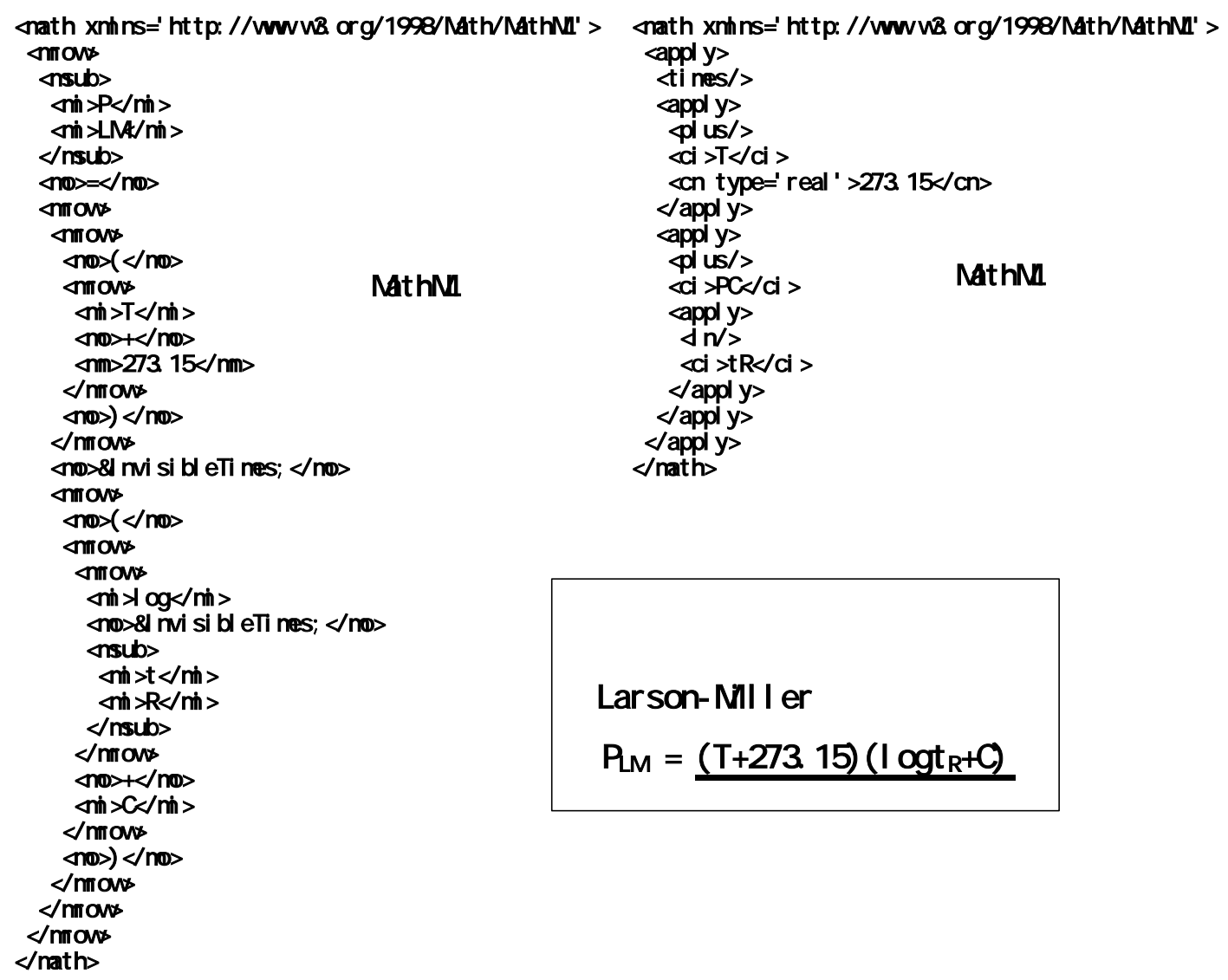

図 4 数式の MathML 記述 


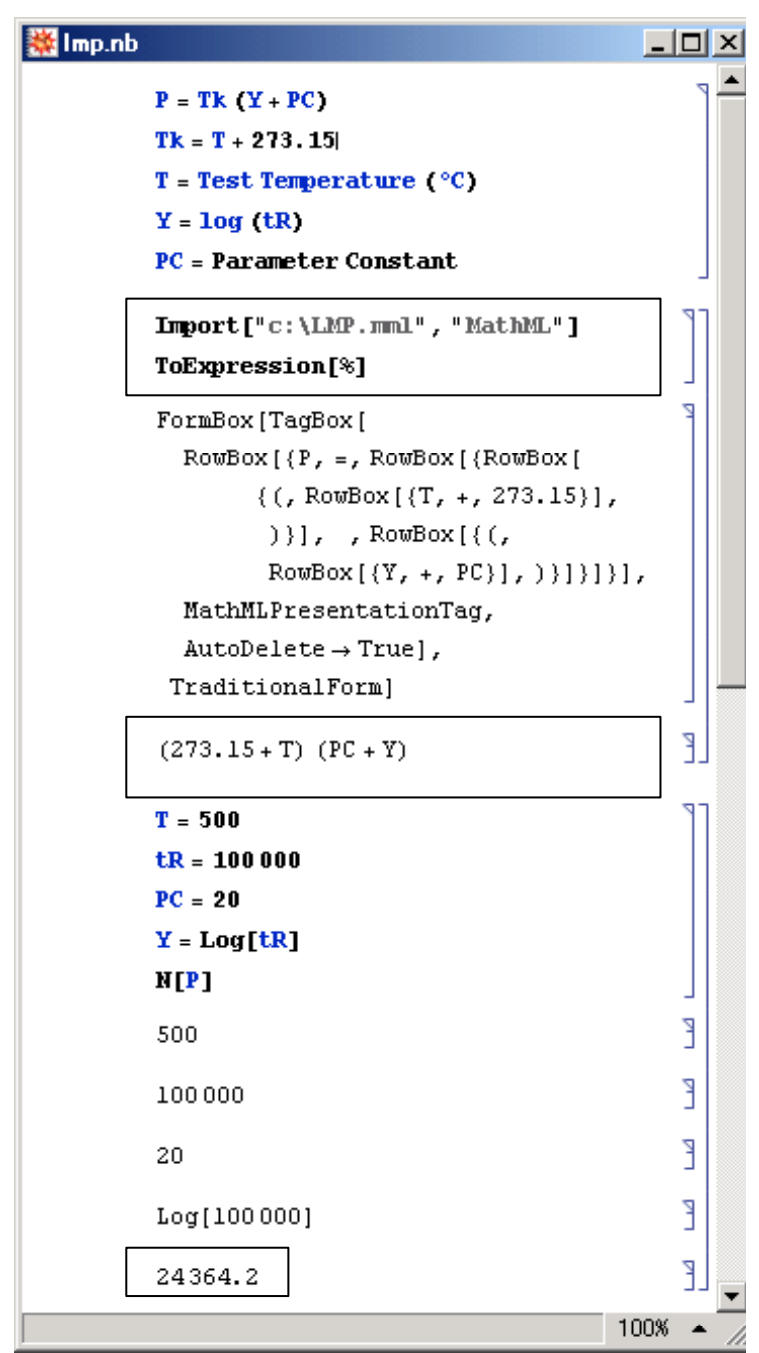

图 5 Mathematica による数式利用例

中間ファイルが必要であり、ソフトウェ アに依存する）が可能となる．また，目 的の計算の省力が可能になり, 計算結果 に材料分野特有のタグが付けられるので 内容の理解がコンピュータにも可能であ る.

\section{5 おわりに}

MathML で記述された材料分野の数式 が Web 上に提供されていると，目的の数 式を選択して Mathematica などのソフト
ウェアに取り込むと目的の数值データ解 析がより用意になる .

ここで，問題点として、

1 ) 数式に用いられる記号が同じでも意 味することが異なる場合があるので、添 え字を含めた文字や記号の意味すること の統一と共有が必要である。

2 ) 材料分野の ML には、数式記述を考 慮して、タグとなる要素に文字や記号の 属性をも指定すべきである .

\section{参考文献}

[1] 芳須 弘他：高度材料情報の的確な 獲得方法の検討, 情報知識学会誌, Vol.15, No.3 , pp.19-30 , 2005

[2] MatML: National Institute of Standards and Technology, in U.S.A., http://www.matml.org/ [3] 材料データベース委員会,材料データ ベースに関する情報収集及び調査研究報 告書, 大阪科学技術センタ一付属二ューマ テリアルセター ,2006

[4] Materials Ontology: http://www.codata.org/ [5] 材料問題解決支援システム: http://www.nims.go.jp/vamas_twa10/test-hp/

[6] MathML: http://www.w3.org/Math/MathML

[7] インターネット版先進材料特性ファクトデ ータベース : http://www.nims.go.jp/vamas_twa10/ [8] Mathematica: Mathematica ver.6.0, Wolfram Research, 2006 